\title{
Perancangan Sistem Monitoring Detak Jantung Bagi Penderita Kardiovaskular Berbasis Internet of Things
}

\author{
${ }^{1}$ Muhamad Bahrul Ulum, ${ }^{2}$ Masmur Tarigan \\ ${ }^{1,2}$ Program Studi Teknik Informatika, Universitas Esa Unggul \\ J1. Arjuna Utara No.9, Duri Kepa, Kec. Kebon Jeruk Kota Jakarta Barat 11510 \\ ${ }^{1}$ m.bahrul_ulum@esaunggul.ac.id, 2masmur.tarigan@esaunggul.ac.id
}

\begin{abstract}
The form of an archipelago and densely populated country of Indonesia has its own constraints in efforts to deal with health, especially health for patients with cardiovascular disease. This disease is one of the highest causes of death in Indonesia. Based on data from the Ministry of Health, cardiovascular disease since 2007 is the highest cause of death in Indonesia with more than 220,000 deaths each year. While the number of cases exceeds tuberculosis, which has a death toll of 127,000 . The number is increasing every year due to changes in lifestyle of Indonesian people who like to eat high-fat foods and lifestyle factors that affect the risk of cardiovascular disease, including lack of physical activity, smoking, high-fat diets, and alcohol consumption habits. This study aims to monitor the heart rate of cardiovascular sufferers with the internet of things (IoT) approach. Every patient with cardiovascular disease can be monitored using a sensor connected to a PC to record any changes that occur. The research method consists of several stages, namely: Prepare, Plan, Design, Implement, Operate and Optimize (PPDIOO). The results obtained in the form of a prototype heart rate monitoring system for patients with cardiovascular. The patient's health can be monitored at any time by the hospital doctor without the patient having to come regularly to the hospital.
\end{abstract}

Keywords: Cardiovascular; Internet of Things; Patients; Real time.

\section{PENDAhUluan}

Negara Indonesia yang berbentuk kepulauan serta berpenduduk padat memberikan kendala tersendiri dalam usaha penanganan kesehatan, terutama kesehatan bagi penderita penyakit kardiovaskular. Penyakit ini adalah salah satu penyebab kematian tertinggi di Indonesia. Berdasarkan data Kementerian Kesehatan, penyakit kardiovaskular sejak tahun 2007 adalah penyebab kematian tertinggi di Indonesia dengan jumlah kematian lebih dari 220.000 jiwa setiap tahun. Sedangkan jumlah kasusnya melampaui penyakit tuberkulosis yang jumlah angka kematiannya mencapai 127.000 jiwa. Angkanya makin bertambah tiap tahun akibat perubahan gaya hidup masyarakat Indonesia yang suka menyantap makanan tinggi lemak serta faktor gaya hidup yang berpengaruh pada risiko penyakit kardiovaskular, antara lain adalah kurangnya aktivitas fisik, merokok, pola makan tinggi lemak, dan kebiasaan mengkonsumsi alkohol.

Telemedika (Telemedicine), merupakan suatu bidang ilmu yang memanfaatkan teknologi dalam bidang teknik elektro dan komputer untuk pelayanan kesehatan jarak jauh. Salah satu aplikasi dalam bidang telemedika adalah Telemonitoring atau pemantauan jarak jauh. Aplikasi telemonitoring dalam penanggulannya penyakit kardiovaskular diantaranya adalah salah satunya monitoring detak kardiovaskular pasien berbasis internet. Melihat tingkat kematian pasien penderita penyakit kardiovaskular yang relatif tinggi, membuat proses monitoring bagi pasien penderita penyakit kardiovaskular sangat diperlukan.

Penelitian terkait dalam bidang sistem monitoring telah dilakukan [1], Sistem pemantauan penyakit jantung untuk layanan perawatan kesehatan [2], Sistem pemantauan pasien berbasis IoT [3], Prototipe sistem pemantau kondisi kesehatan pasien berbasis web [4], serta pemantauan Sistem pemantauan glukosa berkelanjutan berbasis IoT [5]. Tetapi penelitian tersebut belum mengkaji tentang aspek penerapan Internet of Thing untuk monitoring detak jantung khusus pada penderita kardiovaskular. 
Pada penelitian ini bertujuan untuk menerapkan internet of things (IoT) untuk memonitoring detak jantung penderita penyakit kardiovaskular. Setiap pasien penderita radiovaskular bisa dimonitor menggunakan sensor yang terhubung dengan PC untuk mencatat setiap perubahan detak jantung yang terjadi.

Urgensi penelitannya yaitu melihat banyaknya penderita penyakit kardiovaskular, hal ini terutama bagi penderita di pedesaan yang jauh dari jangkauan dokter maka adanya monitoring penderita kardiovaskular berbasis IoT ini akan membantu dalam penanggulangan penyakit kardiovaskular yaitu dengan cara pencatatan detak jantung dalam sistem monitoring yang terkoneksi pada database secara cepat dan tepat untuk menentukan langkah-langkah secara efektif sehingga setiap kondisi pasien dapat dipantau secara langsung (online) dan waktu-nyata (real-time), sehingga data-data detak jantung dan tensi darah dapat setiap saat dipantau oleh tim dokter rumah sakit tanpa pasien harus datang secara rutin ke rumah sakit.

\section{METODOLOGI PENELITIAN}

Metode yang digunakan dalam penelitian ini merupakan metodologi pendekatan dari Cisco system. Metode ini terdiri dari beberapa tahap, yaitu : Prepare, Plan, Design, Implement, Operate dan Optimize (PPDIOO). Berikut tahap-tahap PPDIOO Pada gambar 1.

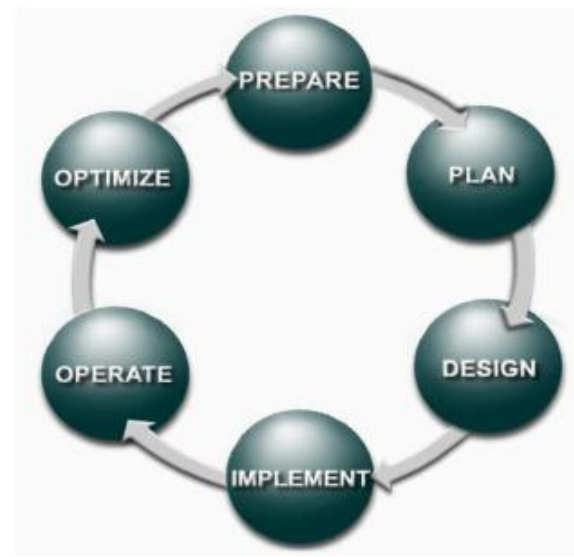

Gambar 1. Metode PPDIOO [6]

\section{Prepare}

Tahap ini diawali dengan menganalisa sistem monitoring penderita kardiovaskular dengan cara melakukan pengumpulan data dilakukan dengan survey lapangan ke RS yang ditujukan untuk memperoleh data primer dan memverifikasi model. Survey dilakukan dengan observasi dan wawancara yang terkait dengan penelitian ini.

\section{Plan}

Tahap ini diawali dengan mengidentifikasi kebutuhan dan dilakukan pengumpulan data dari berbagai pihak yang terkait dalam memonitoring penderita penyakit kardiovaskular.

\section{Design}

Kebutuhan awal yang telah ditentukan pada tahap Plan membentuk kegiatan desain arsitektur IoT diimplementasikan pada dunia kesehatan untuk memonitoring penderita kardiovaskular.

\section{Implement}

Pada tahap ini adalah tahap implementasi dan verifikasi dimulai setelah desain telah disetujui. Jaringan dan komponen sistem tambahan yang dibangun sesuai dengan spesifikasi desain.

\section{Operate}


pengujian akhir dari kesesuaian desain. Pada tahap ini dilakukan pemeliharaan sistem melalui pemantauan sehari-hari, yang mungkin termasuk memelihara ketersediaan dan mengurangi biaya.

\section{Optimize}

Tahap optimize didasarkan pada manajemen sistem proaktif, tujuannya adalah untuk mengidentifikasi dan memecahkan masalah sebelum masalah nyata timbul.

\section{PEMBAHASAN}

\section{A. Pengukuran Detak Jantung}

Untuk mengetahui kondisi/keadaan tubuh pada manusia, bisa diketahui dengan mengukur detak jantung. Pengukuran detak jantung mengacu pada 3 kriteria yaitu jenis kelamin, usia dan aktifitas. Dapat dilihat pada Tabel 1, Tabel 2, dan Tabel 3.

Tabel 1. Detak Jantung Istirahat Laki-Laki [7]

\begin{tabular}{lcccccc}
\hline \multirow{2}{*}{ Kondisi } & \multicolumn{6}{c}{ USIA } \\
\cline { 2 - 7 } & $18-25$ & $26-35$ & $36-45$ & $46-55$ & $56-65$ & $65+$ \\
\cline { 2 - 7 } & \multicolumn{5}{c}{ Detak Jantung (BPM) } \\
\hline Sangat Baik Sekali & $49-55$ & $49-54$ & $50-56$ & $50-57$ & $51-56$ & $50-55$ \\
\hline Sangat Baik & $56-61$ & $55-61$ & $57-62$ & $58-63$ & $57-61$ & $56-61$ \\
\hline Baik & $62-65$ & $62-65$ & $63-66$ & $64-67$ & $62-67$ & $62-65$ \\
\hline Lebih dari Cukup & $66-69$ & $66-70$ & $67-70$ & $68-71$ & $68-71$ & $66-69$ \\
\hline Cukup & $70-73$ & $71-74$ & $71-75$ & $72-76$ & $72-75$ & $70-73$ \\
\hline Kurang & $74-81$ & $75-81$ & $76-82$ & $77-83$ & $76-81$ & $74-79$ \\
\hline Buruk & $82+$ & $82+$ & $83+$ & $84+$ & $82+$ & $80+$ \\
\hline
\end{tabular}

Tabel 2. Detak Jantung Istirahat Perempuan [7]

\begin{tabular}{lcccccc}
\hline \multirow{2}{*}{ Kondisi } & \multicolumn{6}{c}{ USIA } \\
\cline { 2 - 7 } & $18-25$ & $26-35$ & $36-45$ & $46-55$ & $56-65$ & $65+$ \\
\cline { 2 - 7 } & \multicolumn{5}{c}{ Detak Jantung (BPM) } \\
\hline Sangat Baik Sekali & $54-60$ & $54-59$ & $54-59$ & $54-60$ & $54-59$ & $54-59$ \\
\hline Sangat Baik & $61-65$ & $60-64$ & $60-64$ & $61-65$ & $60-64$ & $60-64$ \\
\hline Baik & $66-69$ & $65-68$ & $65-69$ & $66-69$ & $65-68$ & $65-68$ \\
\hline Lebih dari Cukup & $70-73$ & $69-72$ & $70-73$ & $70-73$ & $69-73$ & $69-72$ \\
\hline Cukup & $74-78$ & $73-76$ & $74-78$ & $74-77$ & $74-77$ & $73-76$ \\
\hline Kurang & $79-84$ & $77-82$ & $79-84$ & $78-83$ & $78-83$ & $77-84$ \\
\hline Buruk & $85+$ & $83+$ & $85+$ & $84+$ & $84+$ & $84+$ \\
\hline
\end{tabular}

Tabel 3. Detak Jantung Maksimum dan Target [8]

\begin{tabular}{ccc}
\hline Usia (Tahun) & Target Detak Jantung (50-85\%) & Rata-rata Maksimum Detak Jantung (100\%) \\
\hline 20 & $100-170$ beats per minute $(\mathrm{bpm})$ & $200 \mathrm{bpm}$ \\
\hline 30 & $95-162 \mathrm{bpm}$ & $190 \mathrm{bpm}$ \\
\hline 35 & $93-157 \mathrm{bpm}$ & $185 \mathrm{bpm}$ \\
\hline 40 & $90-153 \mathrm{bpm}$ & $180 \mathrm{bpm}$ \\
\hline 45 & $88-149 \mathrm{bpm}$ & $175 \mathrm{bpm}$ \\
\hline 50 & $85-145 \mathrm{bpm}$ & $170 \mathrm{bpm}$ \\
\hline 55 & $83-140 \mathrm{bpm}$ & $165 \mathrm{bpm}$ \\
\hline 60 & $80-136 \mathrm{bpm}$ & $160 \mathrm{bpm}$ \\
\hline 65 & $78-132 \mathrm{bpm}$ & $155 \mathrm{bpm}$ \\
\hline 70 & $75-128 \mathrm{bpm}$ & $150 \mathrm{bpm}$ \\
\hline
\end{tabular}




\section{B. Arsitektur Sistem}

Arsitektur umum aplikasi IoT dapat dibagi menjadi tiga lapisan: lapisan penginderaan, lapisan transport dan lapisan aplikasi. Gambar 2 menunjukkan Desain Arsitektur Internet of Things untuk monitoring detak jantung penderita kardiovaskular.

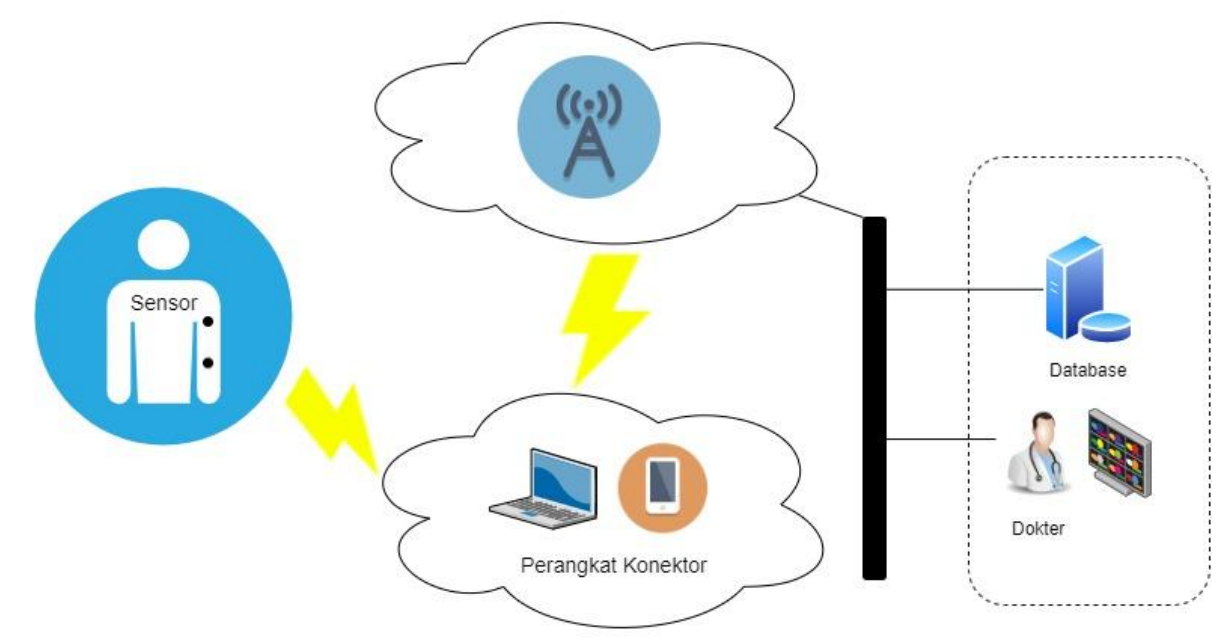

Gambar 2. Arsitektur Sistem Internet of Things Monitoring Detak Jantung

\section{Desain Sistem}

Pada sistem monitoring ini menggunakan mikrokontroller sebagai komponen untuk mengolah data. Mikrokontroller yang digunakan adalah arduino NANO sebagai sistem kendali utama untuk mengontrol semua perintah dan membaca semua data serta ESP8266 sebagai sistem monitoring berbasis IoT yang akan memberikan output berupa grafik dari hasil detak jantung manusia melalui aplikasi. Pada sistem ini pulse sensor akan menghasilkan data yang nantinya akan digunakan untuk mendeteksi detak jantung manusia. Data ini akan diolah oleh arduino untuk mengontrol sistem kerja pulse sensor dalam mendeteksi detak jantung manusia. dapat dilihat pada Gambar 3.

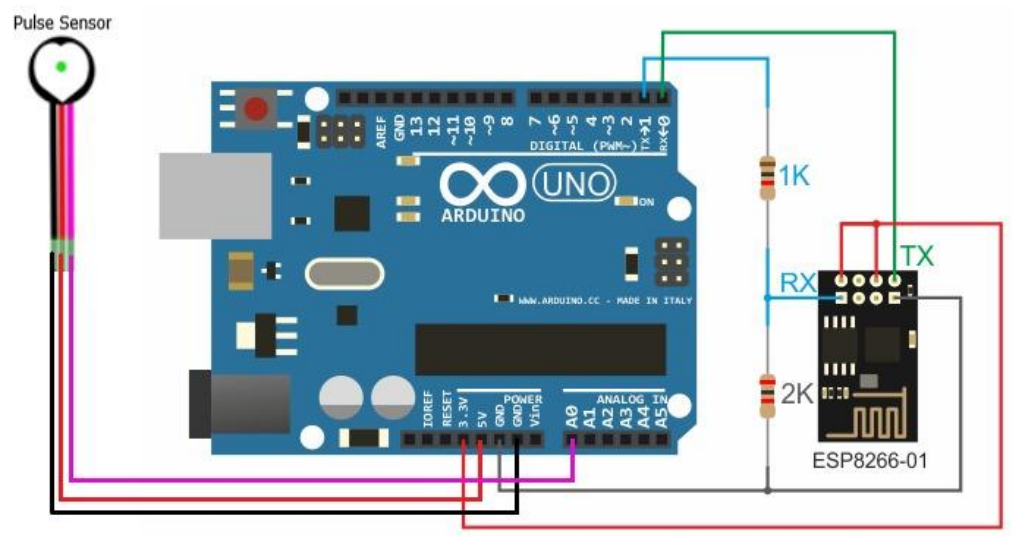

Gambar 3. Desain Sistem

Cara kerja dari alat monitoring detak jantung ini adalah:

1. Sensor detak jantung terhubung ke Arduino NANO.

2. Sensor detak jantung mendeteksi detak jantung melalui pergelangan tangan. 
3. Nilai jumlah detak jantung yang terdeteksi diubah ke dalam digital melalui Analog Digital Converter pada Arduino, selanjutnya ditampilkan ke layar monitor.

4. Data nilai jumlah detak jantung dikirim dan disimpan ke server.

5. Server menampilkan nilai jumlah detak jantung yang diterima pada halaman website yang telah disediakan.

Gambar 8.

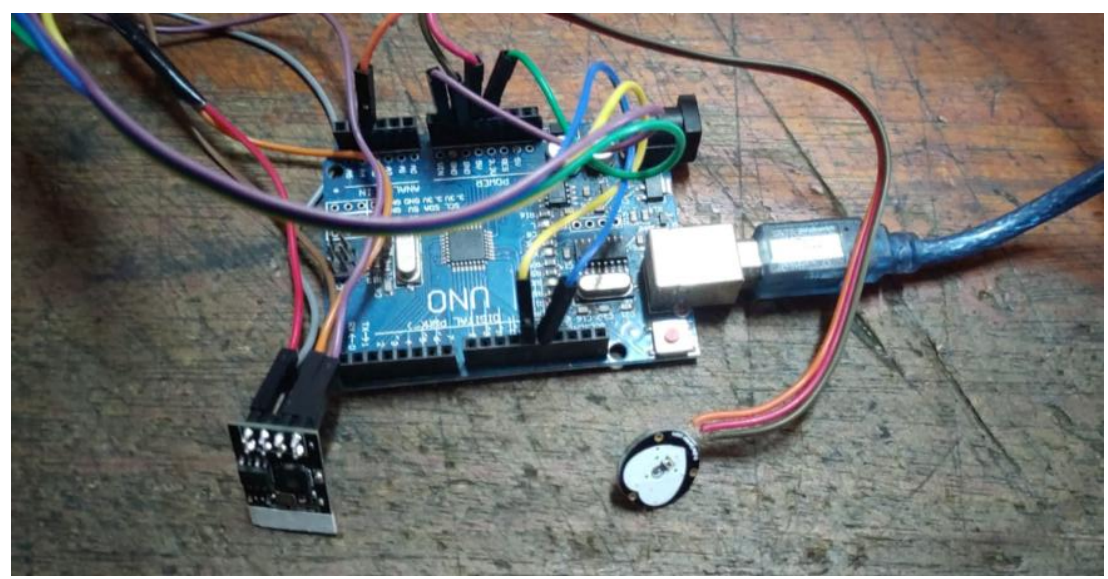

monitoring detak jantung

Prototipe alat

\section{Implementasi Sistem}

Sistem dikembangkan dengan pemrograman arduino. Mikrokontroller yang digunakan adalah arduino NANO serta ESP8266 dan hearbeat sensor sebagai sistem monitoring berbasis IoT yang akan memberikan output berupa grafik dari hasil detak jantung manusia melalui aplikasi.

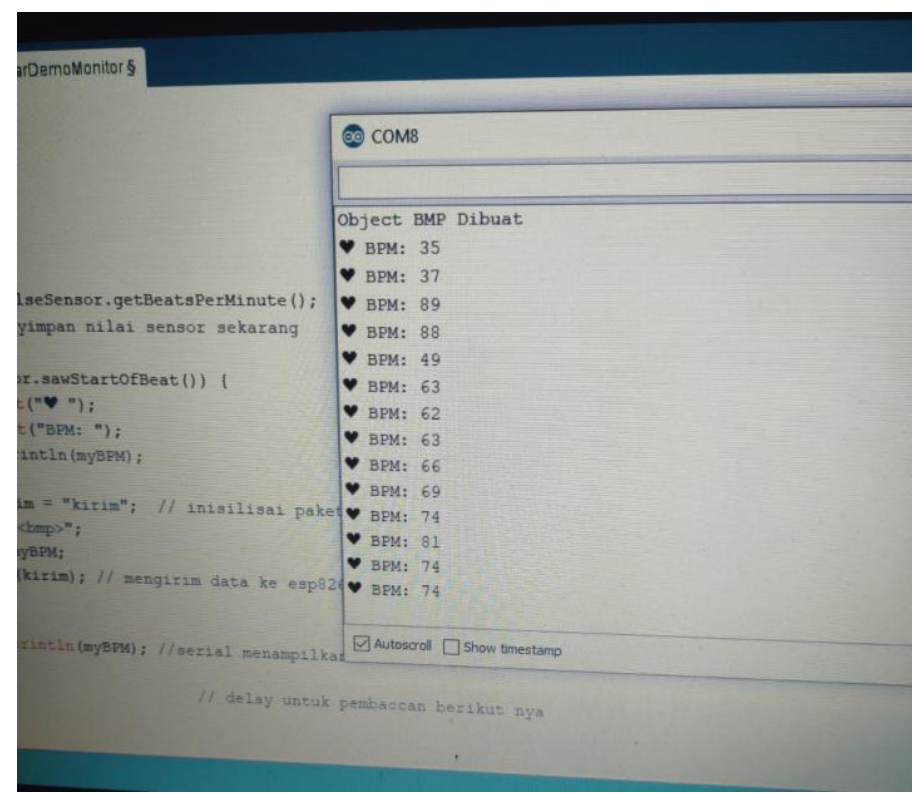

Gambar 9. Tampilan Hasil Monitoring Detak Jantung

\section{KESIMPULAN}

Berdasarkan hasil penelitian didapat berupa prototipe sistem monitoring detak jantung bagi penderita kardiovaskular. Hal ini terutama bagi penderita di pedesaan yang jauh dari jangkauan dokter maka adanya monitoring detak jantung bagi penderita kardiovaskular berbasis IoT ini akan membantu 
dalam penanggulangan penyakit kardiovaskular yaitu dengan cara pencatatan detak jantung dalam sistem monitoring yang terkoneksi pada database secara cepat dan tepat untuk menentukan langkahlangkah secara efektif sehingga setiap kondisi pasien dapat dipantau secara langsung (online) dan waktu-nyata (real-time). Sehingga data detak jantung dan tensi darah dapat setiap saat dipantau oleh tim dokter rumah sakit tanpa pasien harus datang secara rutin ke rumah sakit.

\section{Daftar Pustaka}

[1] R. Adil, "PERANCANGAN SISTEM MONITORING ONLINE PADA PASIEN PENDERITA JANTUNG KORONER," pp. 181-186, 1986.

[2] Z. Li, Chao; Hu, Xiangpei ; Lili, "The IoT-based heart disease monitoring system for pervasive healthcare service.pdf." pp. 2328-2334, 2017.

[3] J. Gómez and B. Oviedo, "Patient Monitoring System Based on Internet of Things," Procedia Procedia Comput. Sci., vol. 83, no. June, pp. 90-97, 2016.

[4] S. Mulyono, "Rancang Bangun Prototipe Sistem Pemantau Kondisi Kesehatan Pasien Berbasis Web," vol. 2, no. 2, pp. 250-259, 2013.

[5] T. N. Gia, M. Ali, I. Ben Dhaou, A. M. Rahmani, T. Westerlund, and P. Liljeberg, "An IoTbased continuous glucose monitoring system : A feasibility study IoT-based continuous glucose monitoring system : A feasibility study," no. May, 2017.

[6] C. Systems, "CREATING BUSINESS VALUE AND OPERATIONAL EXCELLENCE," pp. $1-10,2010$.

[7] TopendSport, "Resting Heart Rate Table," 2019. [Online]. Available: www.topendsports.com/testing/heart-rate-resting-chart.htm.

[8] American Heart Association, "Target Heart Rate," 2019. [Online]. Available: www.heart.org/en/healthy-living/fitness/fitness-basics/target-heart-rates. 